\title{
Traditional Chinese Medicine for Patients of Coronary Artery Disease: Savior or Troublemaker? A Cohort Study About the Adherence to Antiplatelet Therapy
}

J Gen Intern Med 37(4):981-3

DOI: $10.1007 / \mathrm{s} 11606-021-06640-9$

(c) Society of General Internal Medicine 2021

\section{INTRODUCTION}

Coronary artery disease (CAD) is the second leading cause of death in China. ${ }^{1}$ Management of CAD is based on long-term medications including antiplatelet therapy. ${ }^{2}$ In China, traditional Chinese medicine (TCM)-based herbal drugs, which are criticized for lack of clinical evidence, are widely used. ${ }^{3}$ It is common for Chinese patients with CAD to take both aspirin and TCM or even just TCM. Our study purpose was to explore the influence of TCM on patients' decisions about antiplatelet therapy.

\section{METHODS}

This was a cohort study performed in the Fourth Affiliated Hospital of Zhejiang University. From January 1, 2016, to December 1, 2018, all patients undergoing coronary angiography were enrolled if they were diagnosed with $\mathrm{CAD}$ for the first time who consented to participate in this study. We obtained clinical and socioeconomical data and educated participants, prior to discharge on the importance of antiplatelet therapy in patients with CAD. After 6 months, patients were interviewed about their current medication and reasons for discontinuing antiplatelet therapy. An adherence score from 0 to 4 was assigned according to their frequency of taking antiplatelet drugs with a score $\geq 3$ indicative of good medication adherence. Additional questions were asked about the presence of angina within the last month, other newly diagnosed diseases, complications of antiplatelet therapy, and the patient's reasons for discontinuing the medication. The frequency of using TCM was scored from 0 to 4 , with scores $\geq 3$ indicating high use. We excluded patients with contraindications for antiplatelet therapy, patients incapable of medication self-management.

Characteristics were compared between patients with good and poor adherence to antiplatelet therapy. Logistical

Received November 30, 2020

Revised December 23, 2020

Accepted January 25, 2021

Published online February 23, 2021 regression was performed to identify the independent risk factor for the poor adherence (SPSS v 18.0, SPSS, Inc, Chicago, IL).

\section{RESULTS}

Among 1191 patients surveyed at 6 months, 804 (67.5\%) patients had good adherence to antiplatelet drugs, while 387 $(32.5 \%)$ were poorly adherent. Patients with poor adherence to antiplatelet therapy were more likely to report side-effects and regularly used TCM (Table 1). Having medical insurance (OR: $0.640,95 \%$ CI: $0.470-0.873$ ) and having recent angina

Table 1 The Comparisons Between Patients with Good and Poor Adherence to Antiplatelet Therapy

\begin{tabular}{|c|c|c|c|}
\hline Patients characteristics & $\begin{array}{l}\text { Good } \\
\text { adherence } \\
(n=804)\end{array}$ & $\begin{array}{l}\text { Poor } \\
\text { adherence } \\
(n=387)\end{array}$ & $P$ \\
\hline \multicolumn{4}{|l|}{ Demographic factors } \\
\hline Male $(\%)$ & 56 & 59.2 & 0.317 \\
\hline Age (years) & $65.00 \pm 10.17$ & $\begin{array}{l}66.09 \pm \\
10.55\end{array}$ & 0.088 \\
\hline \multicolumn{4}{|l|}{ Social economic factors } \\
\hline Poorly educated (\%) & 46.3 & 52.2 & 0.063 \\
\hline Married (\%) & 82.8 & 78.0 & 0.048 \\
\hline Urban residents (\%) & 65.8 & 61.2 & 0.137 \\
\hline $\begin{array}{l}\text { Covered by medical } \\
\text { insurance }(\%)\end{array}$ & 79.9 & 72.4 & 0.005 \\
\hline \multicolumn{4}{|l|}{ Comorbidities } \\
\hline Hypertension (\%) & 63.3 & 67.2 & 0.196 \\
\hline Diabetes $(\%)$ & 33.0 & 31.5 & 0.644 \\
\hline Ischemic stroke (\%) & 8.8 & 7.8 & 0.580 \\
\hline $\begin{array}{l}\text { Peripheral vascular } \\
\text { disease }(\%)\end{array}$ & 15.2 & 11.6 & 0.109 \\
\hline \multicolumn{4}{|l|}{ CAD-related factors } \\
\hline Current smoker (\%) & 24.4 & 27.1 & 0.319 \\
\hline Regularly drinking (\%) & 33.2 & 33.6 & 0.896 \\
\hline $\begin{array}{l}\text { Family history of } \\
\text { cardiovascular dise }(\%)\end{array}$ & 28.4 & 23.0 & 0.050 \\
\hline $\begin{array}{l}\text { Underwent coronary } \\
\text { invasive therapy }(\%)\end{array}$ & 38.9 & 32.0 & 0.021 \\
\hline Recent angina $(\%)$ & 15.5 & 8.3 & $<0.001$ \\
\hline Side-effects & 19.3 & 42.4 & $<0.001$ \\
\hline Bleeding $(\%)$ & 10.9 & 23.0 & $<0.001$ \\
\hline Other side-effects $(\%)$ & 9.6 & 23.0 & $<0.001$ \\
\hline Use of TCM (\%) & 37.3 & 55.3 & $<0.001$ \\
\hline \multicolumn{4}{|l|}{$\begin{array}{l}\text { Frequency of using TCM } \\
(\%)\end{array}$} \\
\hline 0 & 62.7 & 44.7 & \\
\hline 1 & 16.0 & 8.8 & \\
\hline 2 & 14.3 & 15.0 & \\
\hline 3 & 4.9 & 18.6 & \\
\hline 4 & 2.1 & 12.9 & \\
\hline
\end{tabular}




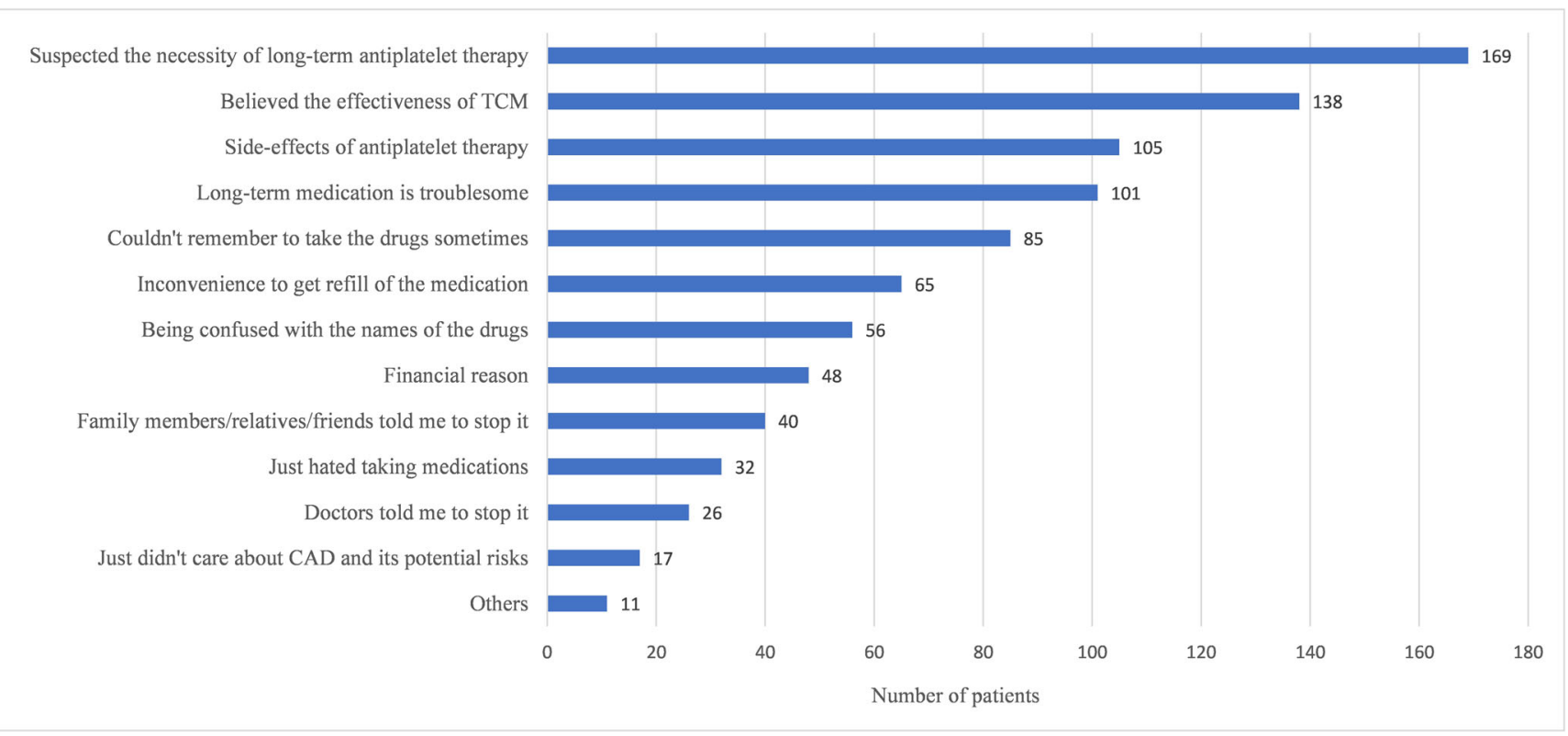

Figure 1 Reasons reported by the patients for their poor-adherence to antiplatelet therapy.

(OR: 0.775 , 95\% CI: 0.635-0.947) both increased adherence to antiplatelet therapy, while experiencing side-effects from antiplatelet drugs (OR: 2.760, 95\% CI: 2.074-3.673) and using TCM (OR 1.591, 95\% CI: 1.434-1.766) decreased adherence to antiplatelet therapy. Spearman's correlation analysis showed that adherence to antiplatelet therapy was negatively correlated to the frequency of using TCM (correlation coefficient: $-0.286 ; P<0.01$ ) and suggested that there was a stepwise decrease of adherence to antiplatelet therapy with increased frequency of using TCM.

Among the reasons of poor adherence to antiplatelet therapy, doubts about the necessity of long-term antiplatelet therapy and belief that TCM was the proper medication for CAD both ranked highly. Other common reasons include side-effects of antiplatelet therapy, trouble caused by long-term medication, and financial reason (Fig. 1).

\section{DISCUSSION}

Poor adherence to antiplatelet therapy among Chinese patients with CAD is quite high. The use of TCM is an important barrier for patients' adherence to antiplatelet therapy. TCM and modern medicine have coexisted in China for decades. Unlike modern medicine, TCM is based on ancient Chinese philosophy such as "yin-yang" and "five elements". ${ }^{4}$ They lack convincing evidence from well-designed studies. ${ }^{5}$ Dozens of TCM are claimed able to promote blood flow and alleviate blood "stagnation" including the products of gingko and danshen, among others, ${ }^{6}$ and are not recommended in Chinese guidelines except as a form of complementary therapy. However, most patients do not read guidelines and are not followed regularly by family doctors in China. They are more familiar with TCM, because their names are usually easier to understand and their medicine instructions are more attractive with magic effects listed and obscure side-effects mentioned. In addition, there is vigorous promotion of TCM on Chinese social media. The wide use of TCM has become a threat to evidence-based medicine and standard management of CAD. This may also be true among Chinese living in other countries, particularly recent immigrants. To improve adherence to antiplatelet therapy among high-risk Chinese patients, greater effort is required to educate patients about evidence-based medicine.

\author{
Chao Feng, M.D. ${ }^{1}$ \\ Fuxu Chen, M.D. ${ }^{1}$ \\ Liang Li, M.D. ${ }^{1}$ \\ Giming Li, M.D. ${ }^{1}$ \\ Shudong Xia, M.D. ${ }^{1}$ \\ ${ }^{1}$ Department of Cardiology, the Fourth Affiliated \\ Hospital of Zhejiang University School of Medicine, \\ Yiwu, China
}

Corresponding Author: ChaoShudong FengXia, M.D.; Department of Cardiology, the Fourth Affiliated Hospital of Zhejiang University School of Medicine, Yiwu, China (e-mail: 8013010@zju.edu.cn).

Funding This work was supported by grants from the National Natural Science Foundation of China (Nos. 81600393, 81971688) and grant from the Education Department of Zhejiang Province (No. Y201942034).

\section{Declarations:}

Conflict of Interest: The authors declare that they do not have a conflict of interest. 


\section{REFERENCES}

1. Zhou M, Wang $\mathbf{H}$, Zeng $\mathbf{X}$, Yin $\mathbf{P}$, Zhu J, Chen W, et al. Mortality, morbidity, and risk factors in China and its provinces, 1990-2017: a systematic analysis for the Global Burden of Disease Study 2017. Lancet. 2019. doi:https://doi.org/10.1016/S0140-6736(19)30427-1

2. Fihn SD, Blankenship JC, Alexander KP, Bittl JA, Byrne JG, Fletcher BJ, et al. 2014 ACC/AHA/AATS/PCNA/SCAI/STS focused update of the guideline for the diagnosis and management of patients with stable ischemic heart disease: a report of the American College of Cardiology/ American Heart Association Task Force on Practice Guidelines, and the American Association for Thoracic Surgery, Preventive Cardiovascular Nurses Association, Society for Cardiovascular Angiography and Interventions, and Society of Thoracic Surgeons. J Thorac Cardiovasc Surg. 2015;149(3):e5-23. doi:https://doi.org/10.1016/j.jtcvs.2014.11.002

3. Yao L, Chen $\mathbf{Y}$, Wang $\mathbf{X}$, Shi $\mathbf{X}$, Wang $\mathbf{Y}$, Guo T, et al. Appraising the quality of clinical practice guidelines in traditional Chinese medicine using
AGREE II instrument: A systematic review. Int J Clin Pract. 2017;71(5). doi:https://doi.org/10.1111/ijcp.12931

4. Cook S. Coronary artery disease, nitric oxide and oxidative stress: the "YinYang" effect-a Chinese concept for a worldwide pandemic. Swiss Med Wkly. 2006; 136(7-8):103-13. 2006/07/smw-11068

5. Chen YB, Tong XF, Ren J, Yu CQ, Cui YL. Current Research Trends in Traditional Chinese Medicine Formula: A Bibliometric Review from 2000 to 2016. Evid Based Complement Alternat Med 2019;2019:3961395. doi:https://doi.org/10.1155/2019/3961395

6. Lim JW, Chee SX, Wong WJ, He QL, Lau TC. Traditional Chinese medicine: herb-drug interactions with aspirin. Singap Med J. 2018;59(5):230-9. doi:https://doi.org/10.11622/smedj.2018051

Publisher's Note: Springer Nature remains neutral with regard to jurisdictional claims in published maps and institutional affiliations. 